\title{
Dementia associated with bilateral carotid occlusions: neuropsychological and haemodynamic course after extracranial to intracranial bypass surgery
}

\author{
Thomas K Tatemichi, David W Desmond, Isak Prohovnik, David Eidelberg
}

\begin{abstract}
A 55 year old man with bilateral internal carotid and unilateral vertebral artery occlusions presented subacutely with profound behavioural and cognitive changes featuring frontal lobe deficits. Neuropsychological testing showed severe cognitive impairment compatible with dementia. Anatomical imaging showed only a small right superior frontal infarction. Cerebral blood flow was severely reduced, with profound hypofrontality and limited hypercapnic reactivity, and cerebral metabolism was reduced primarily in the medial frontal lobes. After right sided extracranial to intracranial cerebral bypass surgery, both flow and metabolism improved, as did behavioural and neuropsychological deficits. Perfusion insufficiency from bilateral carotid occlusions, with secondarily reduced metabolism in the frontal zones bilaterally, may be an unusual cause of a reversible frontal dementia syndrome.
\end{abstract}

(F Neurol Neurosurg Psychiatry 1995;58:633-636)

Department of

Neurology

T K Tatemichi

D W Desmond

I Prohovnik

Department of

Psychiatry

I Prohovnik

Department of

Radiology, Columbia-

Presbyterian Medical

Center, New York New

York, USA

I Prohovnik

Department of

Neurology, Cornell

University Medical

College, North Shore

University Hospital,

Manhasset, New York,

USA

D Eidelberg

Correspondence to: Dr T K Tatemichi, Stroke and Aging Research Project, Neurological Institute, 710

West 168th Street, New

York, NY 10032-3784,

USA.

Received 1 September 1994 and in revised form

19 December 1994.

Accepted 22 December 1994
Perfusion insufficiency has been difficult to document as a cause of dementia. A few examples have been reported, ${ }^{5-9}$ but most lack detailed clinical-haemodynamic correlations. We describe a unique patient with carotid occlusions who presented with profound behavioural change consistent with dementia that improved after extracranial to intracranial (EC-IC) bypass surgery, suggesting that perfusion insufficiency was the cause.

\section{Case report}

A 55 year old practising attorney experienced a profound change in personality and behaviour occurring over several weeks. Coworkers noted that he was disorganised and "swaying in his conversation," and his wife noticed poor memory with odd behaviour, finding him unusually quiet, placid, and unconcerned, especially in social interactions that would otherwise rouse "argumentative and opinionated" behaviour. He had a long standing smoking history, peripheral vascular disease, a history of moderate alcohol use, two previous myocardial infarctions, treated by coronary bypass surgery after the second event, and repair of an aortic abdominal aneurysm two years earlier. Evaluation at a local hospital included two brain CT scans that showed only cerebral atrophy. Cerebral angiography showed complete occlusion of both internal carotid arteries and the intracranial left vertebral artery, with collateral supply through the posterior communicating arteries from a patent but small right vertebral artery and basilar artery. Ophthalmic collateral was present on the left. After cerebral angiography, he developed mild dysarthria and left arm weakness.

On transfer to Columbia-Presbyterian Medical Center one month after the onset of symptoms, abnormalities on medical examination included old surgical scars and absent foot pulses. Blood pressure was $150 / 70 \mathrm{~mm} \mathrm{Hg}$. Neurological examination disclosed mild left arm weakness and an obvious mental status abnormality. $\mathrm{He}$ was fully alert and showed no signs of delirium, but was completely disoriented to time and place. His general behaviour in conversational interaction was laconic, apathetic, hypokinetic, and abulic. He did not speak unless spoken to, responding with a monotonous voice and showing little affect, and was unconcerned about his neurological problem. The patient 
often sat motionless for minutes, staring at the examiner or his surroundings, but at other times he was fidgety and easily distractible. His responses to complex questions indicated defective reasoning ability with a discursive and loosely organised thought process. He accepted ludicrous or illogical remarks and offered confabulatory or ludicrous remarks of his own. His fund of knowledge and remote memory were defective for his level of professional ability. Confrontation naming was impaired. New learning ability was variable, ranging from zero to two items out of three, after a short delay. Mini mental state examination (MMSE) ${ }^{10}$ score was 19 initially, and 23 about two weeks later.

Magnetic resonance imaging showed mild ventricular dilatation and cortical atrophy; mild bilateral, diffuse frontal periventricular ischaemic changes; and a small $(1.5 \times 1 \mathrm{~cm})$ right superior frontal white matter infarction. An electroencephalogram showed generalised, arrhythmic, and frequent theta and delta slowing without an alpha rhythm. Transcranial Doppler showed a low peak velocity and pulsatility index in both middle cerebral arteries, and diffusely high velocity in the basilar artery.

He underwent right sided EC-IC bypass surgery, without operative complications, and was discharged eight days later. After undertaking an outpatient rehabilitation programme, he returned to work as an attorney some six months after surgery.

\section{Methods}

Cognitive function was examined 13 days before and $7,63,168,276$, and 378 days after surgery with a battery of neuropsychological tests. ${ }^{11}$ The MMSE was also given as a measure of global cognitive function. To compare our patient's performance with age matched normal controls, raw test scores were transformed to $\mathrm{z}$ scores, using data from 62 stroke free control subjects (mean age, 63.0 years; mean education, 12.2 years) who were examined as part of another study. ${ }^{11}$ To interpret the magnitude of cognitive change after surgery, we calculated the mean difference (SD) in MMSE score between admission to hospital and about three months in a sample of nine patients with right sided cortical stroke (mean age 62.3 ; mean education, 14.6 years). We regarded this value as a measure of the recovery expected during the early natural history of stroke.

Regional cerebral blood flow was measured at rest and after hypercapnic challenge with $4 \% \mathrm{CO}_{2} 13$ days before and 3,13,90, 174, and 281 days after surgery, using the xenon133 inhalation technique with a commercial 32 detector system (Novo Cerebrograph 32c). ${ }^{12}$ All cerebral blood flow data were analysed by the six unknown model, and flow results are reported as the initial slope index. ${ }^{12}$

Metabolic rates for glucose were estimated 13 days before and 49 days after surgery with ${ }^{18} \mathrm{~F}$-fluorodeoxyglucose (FDG) and PET with the Superpett 3000 tomograph (Scanditronix, Essex, MA). ${ }^{13}$ The method of calculating global and regional metabolic rates for glucose has been described previously. ${ }^{14}$ Frontal, temporal, parietal, and hemispheric regions of interest were defined interactively on reconstructed PET slices.

\section{Results}

NEUROPSYCHOLOGICAL FINDINGS

Thirteen days before surgery, the MMSE score was 23. Neuropsychological testing showed deficits in verbal memory, orientation, executive functions, abstract reasoning, language, visuospatial function, and attention. Our patient's baseline deficits predominantly reflected frontal lobe dysfunction, but included other disturbances consistent with dementia. Postoperatively, the MMSE score was 28 , and cognitive function at day seven was improved compared with baseline performance (fig 1), most noticeably in executive function. By day 63 and up to day 378, the MMSE score was 30 and all cognitive functions had improved appreciably (fig 1 ). In the comparison sample of nine patients with frontal cortical stroke, the mean change in MMSE score (SD) was 2.0 (1.9) over a period of $76 \cdot 1(21 \cdot 0)$ days after stroke. By contrast, the MMSE score of our patient improved by seven points over 76 days, exceeding the mean "spontaneous" improvement by $2 \cdot 6$ SDs.

\section{FINDINGS FOR REGIONAL CEREBRAL BLOOD FLOW}

Preoperatively, normocapnic perfusion was reduced to about $50 \%$ of normal. Flow was maximally reduced in the frontal regions (fig 2 , upper). With hypercapnia, mean hemispheric reactivity was low $(1.45 / \mathrm{mm} \mathrm{Hg}$ bilaterally) with scattered regions of absent reactivity. Postoperatively (day 13), normocapnic perfusion was greatly improved, predominating in the frontal lobes, especially the

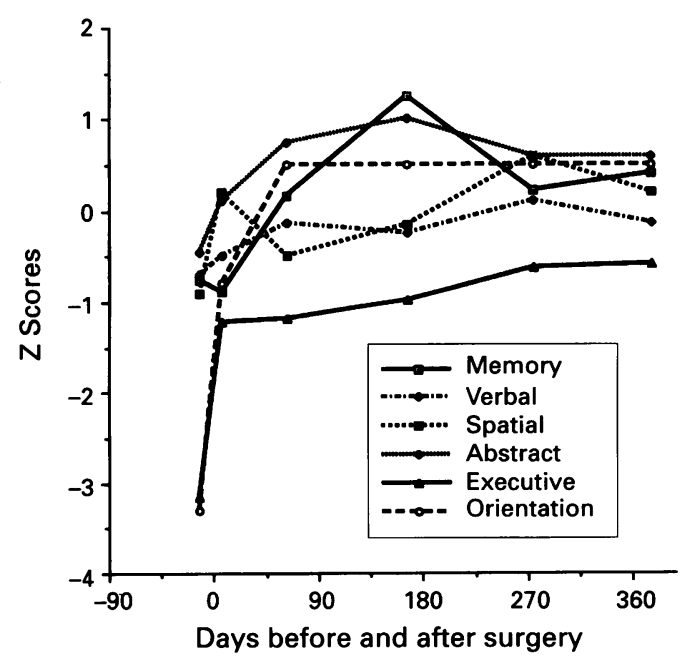

Figure 1 Course of neuropsychological performance before and after EC-IC bypass surgery for six cognitive domains, expressed as $Z$ scores using normative data from stroke free controls. 
Figure 2 rCBF maps showing cortical perfusion 13 days preoperatively (upper panel) and \% change in perfusion after bypass surgery (lower panel). Colours represent perfusion levels (ISI) and colour scale on the left. $\%$ change according to the

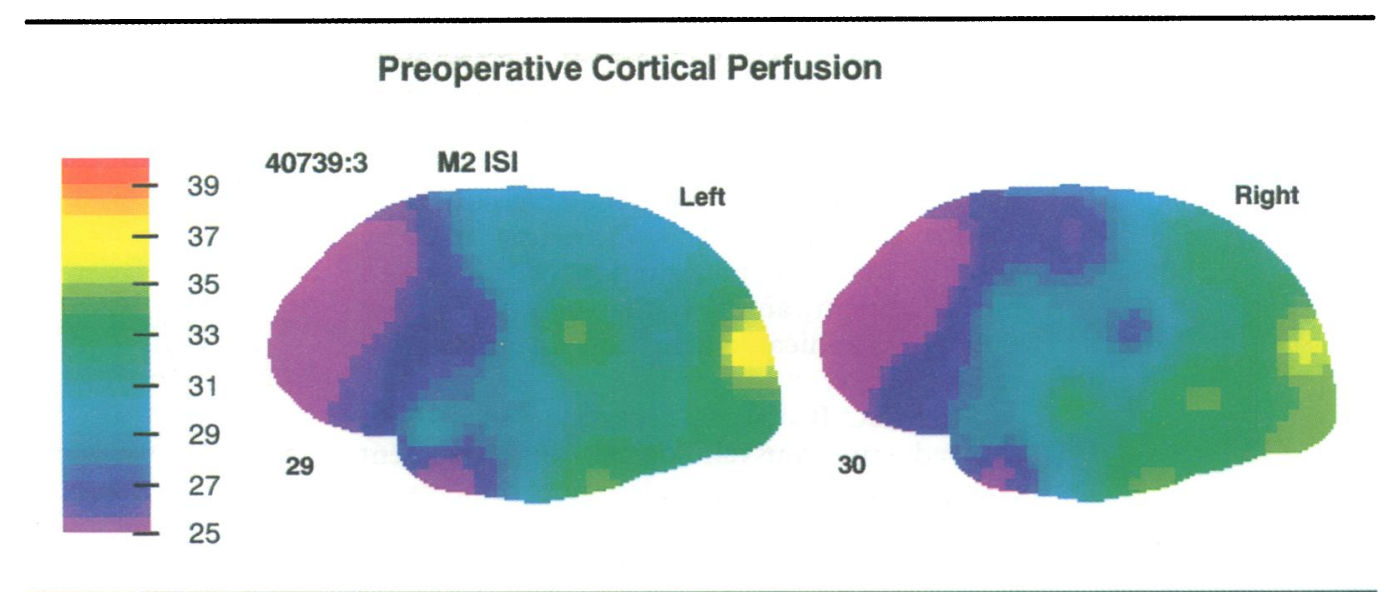

Postoperative Perfusion Changes [\%]
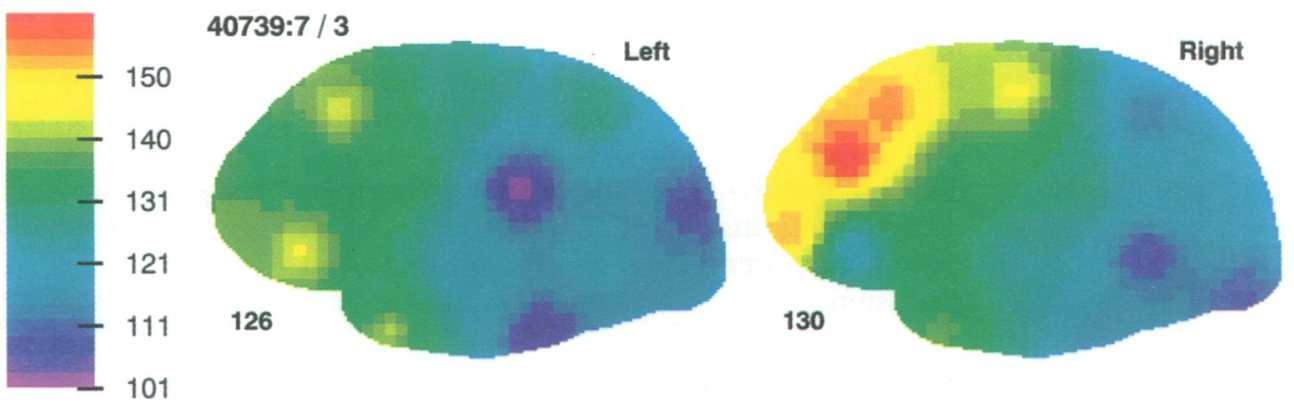

right dorsolateral frontal cortex where there was a $150 \%$ change (fig 2 , lower). Mean hypercapnic reactivity was significantly improved $(2 \cdot 2 / \mathrm{mm} \mathrm{Hg}$ bilaterally). Follow up studies showed sustained improvement in cerebral perfusion, although reactivity fell towards preoperative levels at six months.

\section{FDG/PET FINDINGS}

Preoperatively, the global metabolic rate for glucose was reduced to about $40 \%$ of normal (table 1). Multifocal reductions were evident throughout the neocortex bilaterally, most prominent in the frontal lobes but sparing the occipital cortex. Postoperatively, the global metabolic rate for glucose was unchanged, although a regional increase (exceeding $20 \%$ compared with the preoperative study) was evident in the right medial frontal region.

Normalised regional metabolic rates for glucose $(\mathrm{mg} / 100 \mathrm{~g} / \mathrm{min})$ by region for each side before and after EC-IC bypass surgery, compared with normative data from our laboratory

\begin{tabular}{llllll}
\hline Region & Side & Before & After & \% Change & Normal $^{*}$ \\
\hline Medial frontal & Right & $0.83 \dagger$ & 1.04 & +25 & $0.95(0.05)$ \\
& Left & 0.88 & 0.92 & +4 & $0.97(0.05)$ \\
Lateral frontal & Right & 0.99 & 0.98 & -2 & $1.05(0.04)$ \\
Temporal & Left & $0.87 \dagger$ & 0.97 & +12 & $1.04(0.06)$ \\
& Right & 1.02 & 1.18 & +15 & $1.08(0.06)$ \\
Parietal & Left & $1.28 \dagger$ & 1.02 & -21 & $1.09(0.07)$ \\
Hemisphere & Right & 1.05 & $0.89 \dagger$ & -15 & $1.02(0.05)$ \\
GMR & Left & $1.17 \dagger$ & 1.11 & -5 & $1.03(0.07)$ \\
& Right & $4.98 \dagger$ & $5.15 \dagger$ & +3 & $8.52(1 \cdot 26)$ \\
& Left & $5.06 \dagger$ & $5.03 \dagger$ & -1 & $8.47(1 \cdot 27)$ \\
& - & $5.02 \dagger$ & $5.09 \dagger$ & +1 & $8.30(1 \cdot 19)$ \\
\hline
\end{tabular}

*Values are means (SD), based on 20 subjects, age $47(17 \cdot 1)$ years.

†Differs by $>2$ SDs from normal mean values.

\section{Discussion} due to triple vessel extracranial arterial occlusions was the most likely explanation for our patient's dementia syndrome. Baseline regional cerebral blood flow and PET investigations showed a $40 \%$ to $50 \%$ reduction in flow and metabolism, consistent with levels found in other demented patients. ${ }^{3}$ The regional pattern did not suggest Alzheimer's disease, which typically shows biparietal deficits, or multi-infarct dementia, which often shows focal and asymmetric abnormalities. ${ }^{15}$ Rather, the pattern was strikingly hypofrontal and bilateral, consistent with both the neurobehavioural syndrome that featured frontal lobe deficits and the mechanism of carotid territory perfusion insufficiency. ${ }^{4}$

Most PET studies indicate that flow is coupled to metabolism in both vascular and degenerative dementias, ${ }^{39}$ arguing in general against the contribution of vascular insufficiency to dementia syndromes. None the less, some demented patients with bilateral carotid occlusions have been found to have inappropriately low cerebral blood flow in relation to oxygen metabolism with a focal increase in the oxygen extraction ratio, especially in the frontal regions. ${ }^{9}$ This situation has been termed the "misery-perfusion syndrome," 16 suggesting marginal haemodynamic reserve. Reserve can be satisfactorily measured by hypercapnic reactivity using the xenon regional cerebral blood flow method, as suggested by Herold $e t$ al, ${ }^{17}$ who found a significant correlation between $\mathrm{CO}_{2}$ reactivity and
We propose that haemodynamic insufficiency 
oxygen extraction ratio. The threshold value for vasoreactivity was $1.5 \% / \mathrm{mm} \mathrm{Hg}$ in their study, below which the oxygen extraction ratio was always increased. Impaired vasoreactivity in this range has been associated with haemodynamic transient ischaemic attacks or border zone infarction. ${ }^{4}$ Dementia may be another mode of presentation, as illustrated by our patient, an effect that may depend on the topographical extent and magnitude of reduced flow.

After EC-IC bypass surgery, our patient showed neuropsychological improvement coupled with considerable improvements in flow and metabolism. Increases were most striking in the right frontal cortex with perfusion improving by $50 \%$ (dorsolateral region) and metabolism by $20 \%$ (medial region). By contrast, the two operated patients studied by Gibbs $e t a l^{9}$ did not show improved cognitive function or oxygen metabolism. Thus in any individual patient, there may be a threshold of reversibility that may be difficult to define. In some patients with bilateral carotid occlusion, despite the initial presence of chronic and potentially reversible global ischaemia, delayed neuronal attrition may occur, mitigating any therapeutic effects of improved perfusion.

This work was supported in part by grants R01 NS26179 R01 AG05433, and K08 NS01635 from the National Institutes of Health.

1 Fisher CM. Senile dementia-a new explanation for its causation. Can Med Assoc 7 1951;65:1-7.

2 Paulson GW, Kapp J, Cook W. Dementia associated with bilateral carotid artery disease. Geriatrics 1966;21 159-66.
3 Frackowiak RSJ, Pozzilli C, Legg NJ, et al. Regional cerebral oxygen supply and utilization in dementia. A clini$\mathrm{cal}$ and physiological study with oxygen-15 and positron tomography. Brain 1981;104:753-78.

4 Tatemichi TK, Young WL, Prohovnik I, Gitelman DR, Correll JW, Mohr JP. Perfusion insufficiency in limbshaking transient ischemic attacks. Stroke 1990;21: shaking

5 Ferguson GG, Peerless SJ. Extracranial-intracranial bypass in the treatment of dementia and multiple extracranial arterial occlusion [abstract]. Stroke 1976; 7:13.

6 LeBlanc R, Tyler JL, Mohr G, et al. Hemodynamic and metabolic effects of cerebral vascularization. $\mathcal{f}$ Neurosurg 1987;66:529-35.

7 Yanagihara T, Marsh WR, Piepgras DG, Ivnik RJ. Dementia in bilateral carotid occlusive disease [abstract]. Stroke 1990;21:1-99.

8 Abiko S, Matsunaga T, Yamashita T, Fujii M, Aoki H. Anastomosis of the superficial temporal artery to the middle cerebral artery for occlusive disease of the bilateral internal carotid arteries with dementia. No Shinkei Geka 1990;18:1047-52.

9 Gibbs JM, Frackowiak RSJ, Legg NJ. Regional cerebral blood flow and oxygen metabolism in dementia due to vascular disease. Gerontology 1986;32(suppl 1):84-8.

10 Folstein MF, Folstein SE, McHugh PR. Mini-mental state: a practical method for grading the cognitive state of patients for the clinician. $f$ Psychiatr Res 1975;12:189-98.

11 Tatemichi TK, Desmond DW, Mayeux $\mathrm{R}$, et al. Dementia after stroke: baseline frequency, risks, and clinical features in a hospitalized cohort. Neurology 1992;42:1185-93.

12 Prohovnik I. Data quality, integrity and interpretation. In: Knezevic S, Maximilian VA, Mubrin S, Prohovnik I, Wade J, eds. Handbook of regional cerebral blood flow. Hillsdale, New Jersey: Lawrence Erlbaum, 1988:51-78.

13 Robeson W, Dhawan V, Takikawa S, et al. Super PETT 3000 Time-of-flight PET tomograph: optimization of factors affecting quantitation. IEEE Transactions on factors affecting quantitation.

14 Eidelberg D, Moeller JR, Dhawan V, et al. The metabolic topography of Parkinsonism. $\mathcal{f}$ Cereb Blood Flow Metab 1994;14:783-801.

15 Benson DF, Kuhl DE, Hawkins RA, Phelps ME Cummings $\mathrm{J}$, Tsai SY. The fluorodeoxy-glucose $18 \mathrm{~F}$ scan in Alzheimer's disease and multi-infarct dementia. Arch Neurol 1983;40:711-4.

16 Baron JC, Bousser MG, Rey A, Guillard A, Comar D Castaigne P. Reversal of focal "misery-perfusion syndrome" by extra-intracranial arterial bypass in hemodynamic cerebral ischemia. Stroke 1981;12:454-9.

17 Herold S, Brown MM, Frackowiak RSJ, Mansfield AO Thomas DJ, Marshall J. Assessment of cerebral haemodynamic reserve: correlation between PET parameters dynamic reserve: correlation between PET parameters
and $\mathrm{CO}_{2}$ reactivity measured by the intravenous 133 and $\mathrm{CO}_{2}$ reactivity measured by the intravenous 133 xenon injection tech 